J. Lake Sci.(湖泊科学), 2008, 20(3): 315-322

http://www.jlakes.org. E-mail: jlakes@niglas.ac.cn

(C)2008 by Journal of Lake Sciences

\title{
黑藻对沉积物及土壤中不同形态磷的利用与转化
}

\author{
赵海超 ${ }^{1,2}$, 王圣瑞 ${ }^{1}$, 金相灿 ${ }^{1}$, 步青云 ${ }^{1}$, 刘景辉 ${ }^{3}$ \\ (1: 中国环境科学研究院湖泊生态环境创新基地/国家环境保护湖泊污染控制重点实验室, 北京 100012) \\ (2: 河北北方学院农业科学系, 张家口 075131) \\ (3: 内蒙古农业大学农学院, 呼和浩特 010018)
}

摘 要: 利用同一区域湖泊和河流沉积物及土壤培养黑藻，运用化学连续提取法对底质中磷的不同形态进行分离，同时分析 黑藻生物量及底质中上覆水和间隙水中磷浓度的变化, 并对底质中生物可利用磷进行了估算, 揭示沉水植物对底质中不同形 态磷的利用与转化规律. 结果表明, 底质中弱吸附态磷、可还原性磷(RSP)是黑藻利用的主要磷形态; 土壤与沉积物相比不利 于黑藻生长, 营养水平高的河流沉积物有利于黑藻初期生长, 但容易使其早衰; 沉积物作底质上覆水和间隙水磷浓度主要受 底质中 RSP 含量的控制; 土壤作底质上覆水和间隙水磷浓度主要受弱吸附态磷控制; 黑藻能促进底质中磷向可利用态转化; 黑藻对土壤中生物可利用磷的利用率比沉积物低.

关键词: 沉积物; 磷形态; 沉水植物; 黑藻; 可利用性

\section{Availability and transferring of phosphorus forms by Hydrilla verticillata in the sediment and soil}

\author{
ZHAO Haichao ${ }^{1,2}$, WANG Shengrui ${ }^{1}$, JIN Xiangcan ${ }^{1}$, BU Qingyun ${ }^{1} \&$ LIU Jinghui ${ }^{3}$ \\ (1: State Environmental Protection Key Laboratory for Lake Pollution Control \& Research Center of Lake Eco-environment, Chinese \\ Research Academy of Environmental Sciences, Beijing 100012, P.R.China) \\ (2: Department of Agricultural Science, Hebei North University, Zhangjiakou 075131, P.R.China) \\ (3: College of Agronomy, Inner Mongolia Agriculture University, Huhhot 010018, P.R.China)
}

Abstract: Availability of phosphorus forms of submerged plant in the sediment and soil has been studied using the submerged plant Hydrilla verticillata culturing in different trophic sediments and soil. Different phosphorus forms in sediments and soil were separated by the chemical sequential extraction methods, at the same time the biomass of Hydrilla verticillata, concentrations of phosphorus in overlying water and in interstitial water were also analyzed. Amount of the bioavailable particular phosphorus was estimated by the formula of age available particular phosphorus. The results showed that labile phosphorus (P) and reducible soluble phosphorus (RSP) were the main phosphorus forms for Hydrilla verticillata utilization. The sediment is beneficial for the growth and fade of Hydrilla verticillata at the growth early stage. Phosphorus concentrations of the overlying water and interstitial water were affected mainly by the RSP concentrations in sediments. Phosphorus concentrations of interstitial water in soil were affected mainly by its labile $\mathrm{P}$ concentrations. The submerged plant Hydrilla verticillata promoted available phosphorus transforming, and its utilization rate for available particular phosphorus in soil is lower than that in sediments.

Keywords: Sediments; phosphorus forms; submerged plant; Hydrilla verticillata; availability

富营养化是湖泊水库淡水系统面临的一个严重环境问题. 水体中氮、磷等营养元素大量增加是导致 自然水体富营养化的根本原因. 随着点源污染的治理，以农田排磷为主的非点源磷污染往往是水体中磷 的最主要来源, 而且其所占份额仍在不断增加 ${ }^{[1-2]}$, 农田流失的土壤是营养盐的主要载体, 农田 $90 \%$ 以上的

* 国家重点基础研究发展规划项目(2002CB412304)资助. 2007-03-13 收稿; 2007-08-03 收修改稿. 赵海超, 男, 1974 年生; E-mail: haichaozhao19@163.com. 

营养物流失与土壤流失有关 ${ }^{[3]}$, 流失的土壤也是湖库沉积物的重要来源, 随着水库和水利工程的修建被 淹没的大量耕地, 成为水体重要的污染源 ${ }^{[4]}$, 但是近年来土壤进人水体后营养盐的迁移特性研究相对较 少. 沉积物与上覆水中磷的源、汇关系可相互转化, 因此即使外源磷得到有效的控制, 沉积物中磷的重新 释放仍然可以使水中磷浓度维持较高的水平 ${ }^{[5]}$, 沉积物中不同形态磷的迁移转化规律及其影响因子各不 相同, 从而使湖泊水体修复难度大增. 化学连续提取法是湖泊沉积物中磷形态分离的重要手段 ${ }^{[6-7]}$, 对于 研究沉积物中不同形态磷的迁移转化具有重要的意义. 沉水植物占据了湖泊上覆水和沉积物的主要界面, 对湖泊生态系统物质循环过程具有重要的影响 ${ }^{[8]}$, 近年来广泛用于湖泊水库等水体修复及河流的水体净 化中. 黑藻(Hydrilla verticillata(L.f) Royle), 水鳖科, 黑藻属, 是长江中下游浅水湖泊中重要的沉水植物 之一 ${ }^{[9]}$. 本文利用相同区域不同营养状况的河流与湖泊沉积物及土壤为底质培养黑藻, 通过对底质各形 态磷含量及 $\mathrm{Eh}$ 值变化、间隙水和上覆水中磷浓度及黑藻干物质量变化的分析, 研究沉水植物对土壤和沉 积物中不同形态磷的利用和转化的影响, 为利用沉水植物修复湖泊水库生态系统提供一些理论依据.

\section{1 材料与方法}

\section{1 材料}

所用黑藻取自北京房山区拒马河, 在温室内预培养 $7 \mathrm{~d}$, 选取生长良好长势一致的植株顶枝 $20 \mathrm{~cm}$ 作 试验材料. 沉积物分别取自中国环境科学研究院湖泊 $(\mathrm{HK})$ 和北京后海 $(\mathrm{HH})$, 土壤取自北京朝阳区清河营 村表层土壤(TR)并进行浸水处理(用水浸泡 1 个月, 经过与沉积物类似的浸水过程), 晾干后将沉积物与土 壤分别混匀过篮去除杂质. 三种底质取自相同区域基质构成基本相同，营养状况(表 1), 营养含量 HH 相 对较高、 $\mathrm{HK}$ 相对较低、TR 与 $\mathrm{HK}$ 基本相当. 试验设 5 个试验组, 分别以 2 种沉积物和土壤作底质培养 黑藻( $\mathrm{HH}$ 组、HK 组、TR 组)同时作无植物组(TR 对照组、 $H K$ 对照组). 每组在 $1 \mathrm{~m} \times 1 \mathrm{~m} \times 0.8 \mathrm{~m}$ 的玻蓠缸 内设 16 个 PVC 小桶 $(20 \mathrm{~cm}$ (高) $\times 20 \mathrm{~cm}$ (直径)), 每桶装 $3 \mathrm{~kg}$ 底质, 栽 10 株黑藻 $($ 干重 $0.4 \mathrm{~g})$, 用自来水培养. 玻璃缸内定期补充培养水. 培养 4 个月, 定期取样 5 次 (每次各组取 3 桶). 测植物样干重、沉积物中各形 态磷含量和 $\mathrm{Eh}$ 值、上覆水及间隙水中活性磷(SRP)和总磷(TP)浓度.

表 1 三种底质本底营养环境状况

Tab.1 Three environmental conditions of sediments

\begin{tabular}{cccccc}
\hline 营养状况 & 有机质 $(\%)$ & 总氮 $(\mathrm{g} / \mathrm{kg})$ & 总磷 $(\mathrm{mg} / \mathrm{kg})$ & 无机磷 $(\mathrm{mg} / \mathrm{kg})$ & 有机磷 $(\mathrm{mg} / \mathrm{kg})$ \\
\hline $\mathrm{HH}$ & 8.02 & 3.45 & 1264.19 & 735.99 & 528.20 \\
$\mathrm{HK}$ & 2.41 & 1.24 & 687.62 & 578.68 & 108.49 \\
$\mathrm{TR}$ & 2.27 & 1.16 & 781.73 & 626.23 & 155.50 \\
\hline
\end{tabular}

\section{2 方法}

沉积物间隙水提取: 取新鲜沉积物样品于 $250 \mathrm{ml}$ 离心桶中, 在 $25^{\circ} \mathrm{C}$ 下 10000 转 $/ \mathrm{min}$ 离心 $10 \mathrm{~min}$ 使固 液分离, 上清液为间隙水, 沉积物冷冻干燥过 100 目篮备用. 水体中 TP 浓度, 采用消解锄兰比色法测定, SRP 浓度, 过 $0.45 \mathrm{~m}$ 滤膜锄兰比色法测定 ${ }^{[10]}$. 沉积物磷形态分级, 采用连续浸提法 ${ }^{[11-12]}$, 称取沉积物 $1 \mathrm{~g}$ 于 $100 \mathrm{ml}$ 离心筒中加浸提剂 $50 \mathrm{ml}$, 震荡、离心、过滤, 钿锑抗比色法测定浸提夜中磷含量(提取流程见表 2). 生物可利用的非石灰性磷 (NAIP) $=$ labile P+ RSP $+\mathrm{Fe} / \mathrm{Al}-\mathrm{P}$. 底质中 $\mathrm{Eh}$ 值, 采用 $250 \mathrm{~A}$ 型氧化还原电位测量 仪测定, 每个样品重复测定三次.

\section{2 结果与分析}

\section{1 底质中不同形态磷的变化}

沉积物中磷的存赋形态因分级方法及研究目的各不相同, 本试验底质中磷的存赋形态分为, 弱结合 态磷、可还原态磷 $(\mathrm{RSP}) 、$ 铁铝氧化物结合态磷 $(\mathrm{Fe} / \mathrm{Al}-\mathrm{P})$ 、钲结合态磷 $(\mathrm{Ca}-\mathrm{P})^{[14]}$. 各试验组底质中弱结合 态磷含量随着培养时间的延长均呈下降趋势(图 1a). 有植物组下降幅度先快后慢, 含量大小顺序为 TR 组 
$>\mathrm{HH}$ 组 $>\mathrm{HK}$ 组, 在黑藻生长期内下降幅度有植物组大于无植物组. 可能是因为前期黑藻生长较快所以 对底质中磷利用较多后期黑藻衰退利用变少，HH 组 $127 \mathrm{~d}$ 时含量升高可能是植物腐烂所致，而其他两 组生物量较低腐烂沉积作用对底质中磷影响较小. 表明弱结合态磷易于向水体释放及被黑藻根系吸收 利用 ${ }^{[15-16]}$, 淹水土壤比沉积物中的弱结合态磷易于向水体释放及被黑藻根系吸收利用, 河流比湖泊沉 积物中的弱结合态磷易于向水体释放及被黑藻根系吸收利用. 因为弱结合态磷是利用 $\mathrm{HN}_{4} \mathrm{Cl}$ 提取的, 代表了松散吸附的磷，当沉积物环境条件变化或受到扰动时，被沉积物弱吸附的活性磷最容易进人水 层中及被植物吸收利用, 土壤最初的暴露, 微生物生长营造了好氧条件, 导致了微生物的快速生长, 使磷富集于生物体; 当再淹水时, 磷将从微生物细胞中释放出 ${ }^{[17]}$, 从而使土壤中弱结合态磷比沉积物 中的更加活跃.

\section{表 2 底质磷形态分级连续浸提方法}

Tab.2 The sequential extractions of phosphorus forms in sediments

\begin{tabular}{|c|c|c|}
\hline 磷形态 & 提取方法(浸提剂、温度、震荡) & 主要成分 \\
\hline 弱吸附态磷 & $\begin{array}{l}\text { 在 } 100 \mathrm{ml} \text { 离心筒中加人 } 1 \mathrm{~g} \text { 沉积物样, 加人 } 50 \mathrm{ml} 1 \mathrm{~mol} / \mathrm{L} \mathrm{NH}{ }_{4} \mathrm{Cl} \text { 浸提剂, 在 } \\
(25 \pm 1)^{\circ} \mathrm{C}, 200 \text { 转 } / \mathrm{min} \text { 条件下恒温震荡 } 0.5 \mathrm{~h} \text {, 在 } 5000 \text { 转 } / \mathrm{min} 25^{\circ} \mathrm{C} \text { 离心 } \\
10 \mathrm{~min} \text { 使得得固液分离, 钼锑抗比色法测定浸提液中磷含量. }\end{array}$ & $\begin{array}{l}\text { 沉积物中浮游植物细胞内的 } \\
\text { 磷和吸附于颗粒物中水合氧 } \\
\text { 化物表面磷 }^{[13]}\end{array}$ \\
\hline 可还原态磷(RSP) & $\begin{array}{l}\text { 在上步残渣中加人 } 0.11 \mathrm{~mol} / \mathrm{L} \mathrm{NaHCO}_{3}-\mathrm{NaS}_{2} \mathrm{O}_{3} 50 \mathrm{ml} \text {, 在 } 40^{\circ} \mathrm{C}, 200 \text { 转 } / \mathrm{min} \text { 条 } \\
\text { 件下恒温震荡 } 1 \mathrm{~h} \text {, 在 } 5000 \text { 转 } / \mathrm{min} 25^{\circ} \mathrm{C} \text { 下离心 } 10 \mathrm{~min} \text { 固液分离, 钼锑抗比色 } \\
\text { 法测定浸提液中磷含量. }\end{array}$ & $\begin{array}{l}\text { 主要是 } \mathrm{Fe}_{2} \mathrm{O}_{3} \text { 胶膜所包蔽的 } \\
\text { 还原溶性磷酸铁以及磷酸铝 }\end{array}$ \\
\hline 金属氧化物结合 & 在上步残渣中加人 $1 \mathrm{~mol} / \mathrm{L} \mathrm{NaOH} 50 \mathrm{ml}$, 在 $(25 \pm 1){ }^{\circ} \mathrm{C}, 200$ 转 $/ \mathrm{min}$ 条件下恒 & 主要是颗粒物中被铁、铝水 \\
\hline 态磷(Fe/Al-P) & $\begin{array}{l}\text { 温震荡 } 16 \mathrm{~h} \text {, 在 } 5000 \text { 转 } / \mathrm{min} 25^{\circ} \mathrm{C} \text { 下离心 } 10 \mathrm{~min} \text { 固液分离, 钼锑抗比色法测 } \\
\text { 定浸提液中磷含量. }\end{array}$ & $\begin{array}{l}\text { 合氧化物吸附的磷和一部分 } \\
\text { 铁铝磷酸盐 }{ }^{[13]}\end{array}$ \\
\hline 钲结合态磷(Ca-P) & $\begin{array}{l}\text { 在上步残渣中加人 } 0.5 \mathrm{~mol} / \mathrm{L} \mathrm{HCl} 50 \mathrm{ml} \text {, 在 }(25 \pm 1){ }^{\circ} \mathrm{C}, 200 \text { 转 } / \mathrm{min} \text { 条件下恒温 } \\
\text { 震荡 } 16 \mathrm{~h} \text {, 在 } 5000 \text { 转 } / \mathrm{min} 25^{\circ} \mathrm{C} \text { 下离心 } 10 \mathrm{~min} \text { 固液分离, 钼锑抗比色法测定 } \\
\text { 浸提液中磷含量. }\end{array}$ & 主要是磷灰石磷 ${ }^{[13]}$ \\
\hline
\end{tabular}
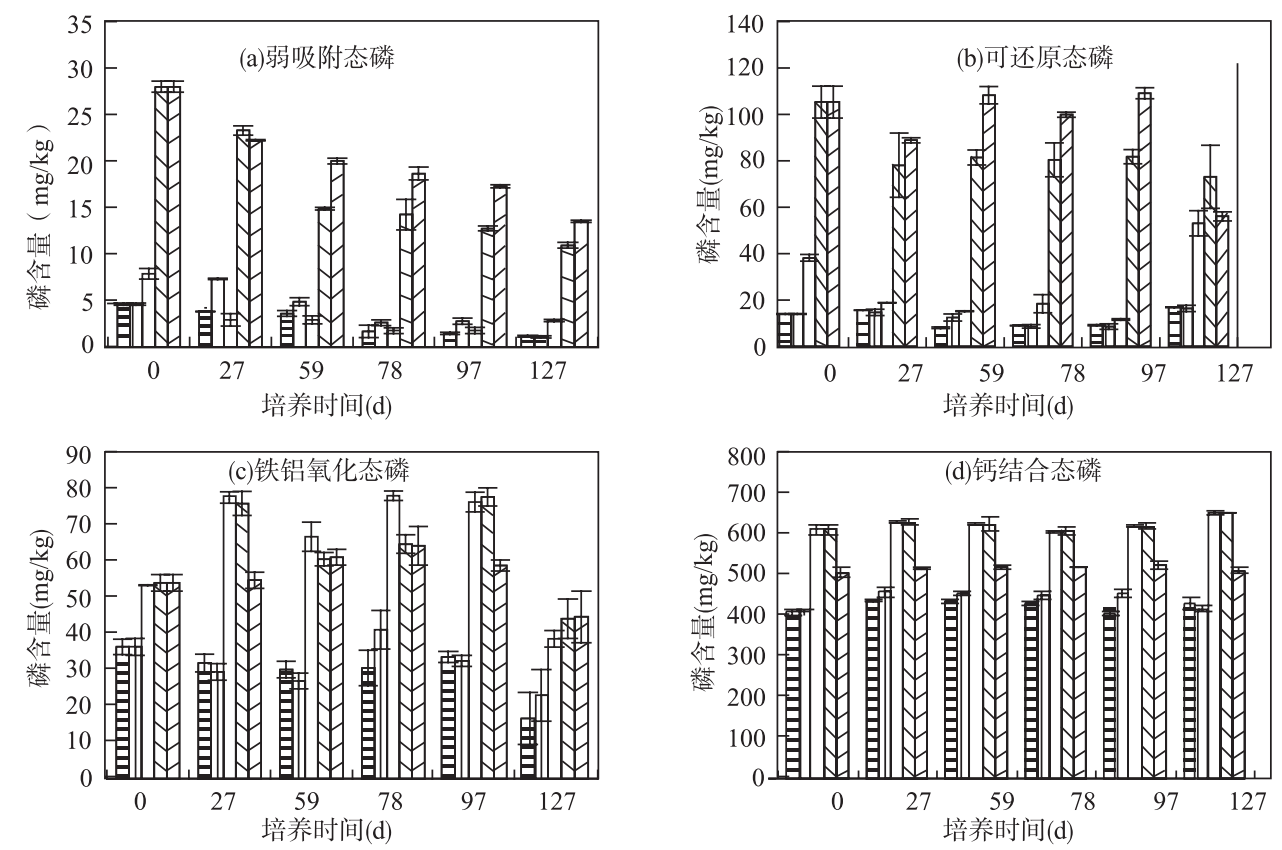

目HK $\square$ HK对照 $\square$ HH $、 T R \quad \square T R$ 对照

图 1 底质中不同形态磷变化

Fig.1 Variability of the phosphorus forms in the sediments 
底质中 RSP 含量随着培养时间的延长各试验组变化趋势不同, 无植物组变化不大. 有植物组在黑藻 生长期(0-97d)内，随着培养时间的延长均呈下降趋势，下降幅度先快后慢，大小顺序为 $\mathrm{TR}$ 组 $>\mathrm{HH}$ 组 $>\mathrm{HK}$ 组, 97d 后 HH、HK 组有所上升, TR 组下降的原因可能是黑藻腐烂沉积和其他形态磷的转化所致, 而 TR 组生物量较小及后期黑藻未完全枯死(图 1b). 表明淹水土壤比沉积物中的 RSP 易于向水体释放及被黑 藻利用, 河流比湖泊沉积物中 RSP 易于向水体释放及被黑藻利用. RSP 易被黑藻利用 ${ }^{[15-16]}$, 沉水植物能促 进底质中 RSP 的释放. 因为 RSP 在底质中的转化主要是化学键的断裂与合成, 受环境因子影响较大. 沉 积物中 $\mathrm{Eh}$ 值升高, 有利于根区附近三价铁的生成和沉淀, 以及根区铁氧化膜的生成 ${ }^{[18]}$, 由于高价铁对磷 具有强烈的吸附作用, 从而使 RSP 的含量急剧升高. 沉水植物可以通过影响环境因子促进 RSP 的释放与 沉淀. 因为水生植物光合放氧使上覆水中含氧量升高, 向上层沉积物中扩散, 使上层沉积物中氧化性升 高. 底质中 Eh 值变化如表 3 所示, HK 组、TR 组呈下降趋势, $97 \mathrm{~d}$ 下降到最低, $127 \mathrm{~d}$ 有所升高. HH 组前期 呈上升趋势, $97 \mathrm{~d}$ 下降至最低, $127 \mathrm{~d}$ 有所升高. 可能是因为, HH 组生物量较高对底质 $\mathrm{Eh}$ 值影响明显, 而 $\mathrm{Hk}$ 组、 TR 组生物量较小, 所以黑藻对底质 $\mathrm{Eh}$ 值影响较小. 而底质的前期暴露使含氧量较高, 淹水后含 氧量下降, $97 \mathrm{~d}$ 时植物腐烂耗氧增加, HH 组 Eh 值出现负值. 由此可见 RSP 在底质的转化受黑藻吸收和黑 藻对环境改变的影响.

$\mathrm{Fe} / \mathrm{Al}-\mathrm{P}$ 变化如图 1(c)所示, 各试验组 Fe/Al-P 含量在 0-97d 时略有上升, $97 \mathrm{~d}$ 之后下降, 有植物组上 升和下降幅度大于无植物组, 含量变化幅度 $\mathrm{HH}$ 组 $>\mathrm{TR}$ 组 $>\mathrm{HK}$ 组. 因为根系的生长使沉积物处于好氧状 态, $78 \mathrm{~d}$ 时底质中 Eh 值有所升高, 好氧状态下, 沉积物增加铁铝氧化物束缚磷酸盐的能力; $97 \mathrm{~d}$ 之后根系 腐烂使沉积物处于戻氧状态 Eh 值下降(表 3), 增加 Fe/Al-P 的释放能力 ${ }^{[11,19]}$. 根据测定水体中溶解性氧的 含量, 厌氧加速沉积物中磷的释放, 好氧抑制磷的释放, 两者差一个数量级 ${ }^{[20]}$. 可见沉水植物主要通过 改变环境影响底质中 Fe/Al-P 的转化. 土壤中 Fe/Al-P 的活性大于营养水平相当的沉积物, 河流沉积物中 $\mathrm{Fe} / \mathrm{Al}-\mathrm{P}$ 的活性大于湖泊沉积物, 可能是因为土壤前期含氧量较高及结构比较松散, 淹水后氧化环境变化 大, Fe/Al-P 含量变化较大. 流动水体中的沉积物进人静止水体, 氧通量减少, Fe/Al-P 的活性增大.

Ca-P 变化如图 1(d)所示, 随着培养时间的延长总体上各试验组底质 Ca-P 含量变化不大, $127 \mathrm{~d}$ 时有所 升高, 可能是因为黑藻腐烂沉积所致. 表明黑藻对沉积物中 $\mathrm{Ca}-\mathrm{P}$ 利用性较小 ${ }^{[21]}$, 沉水植物能够使水体中 活性磷转化为活性较小的钲结合态磷沉积于底质中.

表 3 不同底质 $\mathrm{Eh}$ 值变化

Tab.3 Variability of the Eh in different sediments

\begin{tabular}{cccccc}
\hline \multirow{2}{*}{ Eh 值 } & \multicolumn{5}{c}{ 培养时间 $(\mathrm{d})$} \\
\cline { 2 - 6 } & 27 & 59 & 78 & 97 & 127 \\
\hline HK & $368.1 \pm 6.7$ & $157.4 \pm 8.9$ & $365.9 \pm 10.2$ & $83.9 \pm 2.8$ & $166.4 \pm 3.6$ \\
HK 对照 & $370.2 \pm 4.8$ & $277.3 \pm 2.9$ & $192.5 \pm 6.2$ & $125.2 \pm 8.5$ & $236.5 \pm 4.1$ \\
TR & $380.5 \pm 7.9$ & $297.0 \pm 6.8$ & $317.4 \pm 5.6$ & $261.6 \pm 7.3$ & $319.0 \pm 6.2$ \\
TR 对照 & $374.2 \pm 3.1$ & $265.3 \pm 5.4$ & $178.8 \pm 1.8$ & $261.7 \pm 3.7$ & $177.4 \pm 3.8$ \\
HH & $241.5 \pm 8.2$ & $249.0 \pm 7.3$ & $256.1 \pm 6.1$ & $-17.1 \pm 2.4$ & $180.7 \pm 5.6$ \\
\hline
\end{tabular}

\section{2 底质对黑藻干重变化的影响}

随着培养时间的延长黑藻干重呈 “抛物线” 型变化(图 2). 0-27d 为快速增长期, 在第 $27 \mathrm{~d}$ 达到最大值, 各试验组干重大小顺序为 $\mathrm{HH}>\mathrm{HK}>\mathrm{TR}$, 以后逐渐下降, 在第 $97 \mathrm{~d}$ 全部腐烂, 其中 $\mathrm{HH}$ 试验组在 $78 \mathrm{~d}$ 时已 经腐烂.

对黑藻干重 $(y)$ 及培养天数 $(x)$ 进行非线性回归分析, 方程为 $y=a x+b x^{2}+c$ 获得各试验组黑藻生长方程 (表 4). $a$ 值均为负值、 $b$ 值均为正值, $a$ 值表示黑藻衰退系数, $b$ 值表示黑藻生长系数. 根据 $a$ 值大小可见 各试验组的衰退顺序为 $\mathrm{HH}>\mathrm{HK}>\mathrm{TR}$, 根据 $b$ 值大小可见黑藻生长顺序为 $\mathrm{HH}>\mathrm{HK}>\mathrm{TR}$. 三种底质基质构 成基本相同, 因此物理性状对黑藻生长的影响差异相对较小, 结果表明, 以土壤作底质与营养水平相当 的沉积物作底质相比不利于黑藻生长, 这可能是淹水土壤磷活性大于沉积物, 使上覆水体中磷含量较高, 
抑制黑藻生长. 陈国祥 ${ }^{[22]}$ 等在研究中发现过高的磷水平会 抑制菱及睡莲叶的光合和呼吸速率. 与沉积物相比, 河流沉 积物有利于黑藻初期生长, 但使其早衰. 可能是因为营养含 量较高, 黑藻前期生物量快速增长引起水体缺氧, 促进了沉 水植物的早衰, 表明营养含量高的沉积物不利于沉水植物 恢复.

3 种底质中不同形态磷同黑藻干重相关分析(见表 5). 各 试验组底质中弱结合态磷与黑藻干重均呈显著正相关, 表明 黑藻主要利用底质中弱结合态磷; HK 组底质中 RSP 与黑藻干 重呈极显著正相关, 可能是 $\mathrm{HK}$ 组底质中弱结合态磷含量较 少, 所以黑藻更多的利用了底质中 RSP; 各组 Fe/Al-P 与黑藻 干重相关系数均较小, 可能是因为铁铝氧化物有较强的束缚 磷酸盐的能力 ${ }^{[21]}$, 受环境条件影响较大.

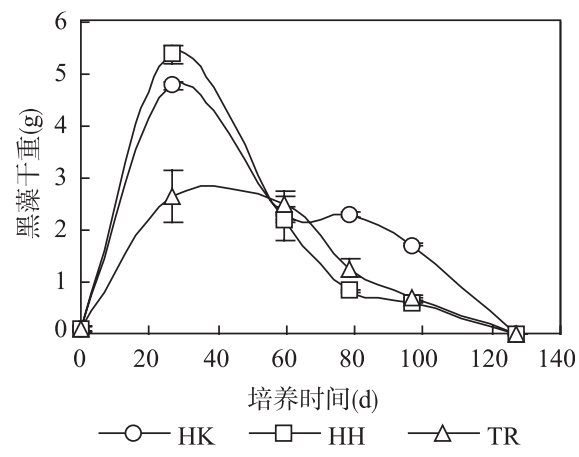

图 2 不同底质培养黑藻干重变化

Fig.2 Variability of the Hydrilla verticillata dry weight in the different sediments

表 4 不同底质培养黑藻生物量生长曲线方程

Tab.4 The parameters of biomass equation of Hydrilla verticillata in different sediments

\begin{tabular}{cccc}
\hline 参数 & HK & HH & TR \\
\hline$a$ & -0.0011 & -0.0014 & -0.001 \\
$b$ & 0.1113 & 0.1197 & 0.0941 \\
$c$ & 0.8188 & 1.0103 & 0.3195 \\
$R^{2}$ & 0.5031 & 0.5203 & 0.8611 \\
\hline
\end{tabular}

表 5 底质不同形态无机磷与黑藻干重相关系数

Tab.5 The parameters of the Hydrilla verticillata dry weight and the inorganic phosphorus forms in the sediments

\begin{tabular}{lllll}
\hline \multirow{2}{*}{ 相关系数 $\left(r^{2}\right)$} & \multicolumn{3}{c}{ 黑藻干重 } \\
\cline { 2 - 5 } & labile P & RSP & Fe/Al-P & Ca-P \\
\hline HK & $0.83^{*}$ & $0.95^{* *}$ & -0.03 & 0.62 \\
HH & $0.80^{*}$ & 0.57 & 0.09 & $0.78^{*}$ \\
TR & $0.76^{*}$ & -0.59 & -0.30 & -0.55 \\
\hline
\end{tabular}

*在 0.05 水平上显著相关, **在 0.01 水平上显著相关; 样本数 $n=5$.

\section{3 底质中不同形态磷对上覆水及间隙水中磷浓度变化的影响}

沉水植物在生长过程中可以吸收和同化水体中的磷, 所以上覆水中磷浓度是影响沉水植物生长的重 要因素. 各试验组上覆水中磷浓度变化(图 3). 各试验组上覆水中 SRP 浓度随培养时间延长变化不同, 总 体来说, 各无植物组先下降, $27 \mathrm{~d}$ 以后趋于平衡. 各有植物组呈 “抛物线” 型变化, 均在 $59 \mathrm{~d}$ 时达到最大 值, 大小顺序为 $\mathrm{TR}>\mathrm{HK}>\mathrm{HH}$, 在第 $97 \mathrm{~d}$ 后趋于平衡, 趋近于无植物组. TP 浓度变化趋势基本与 SRP 相同, 只是最大值出现在第 $71 \mathrm{~d}$ (图 3b). 表明沉水植物可以促进底质中磷向水体中释放 ${ }^{[23]}$, 主要吸收水体中 SRP, 促使总磷向 SRP 转化使总磷峰值出现晚于 SRP. TR 组高于 HK 和 HH 组, 表明淹水土壤比营养水平相当 的沉积物中的磷易于释放. 因为土壤最初的暴露, 好氧导致了微生物的快速生长, 使磷富集于生物体, 当再淹水时, 将从微生物细胞中释放出磷 ${ }^{[24]}$. $59 \mathrm{~d}$ 后 $\mathrm{HK}$ 组高于 $\mathrm{HH}$ 组, 可能是因为 $\mathrm{HH}$ 组黑藻生物量的 增长大于 $\mathrm{HK}$ 组, 所以吸磷较多.

对上覆水中 TP 含量与沉积物中各形态磷进行相关分析可见, HK 组和 HH 组以 RSP 相关性达到显著 性水平 $(P<0.05, n=7)$, TR 组以弱结合态磷相关性达到显著性水平. 表明沉积物作底质上覆水中磷浓度主要 受底质中 RSP 的控制. 土壤作底质上覆水中磷浓度主要受底质中 labile P 的控制. 可能是因为淹水土壤中 

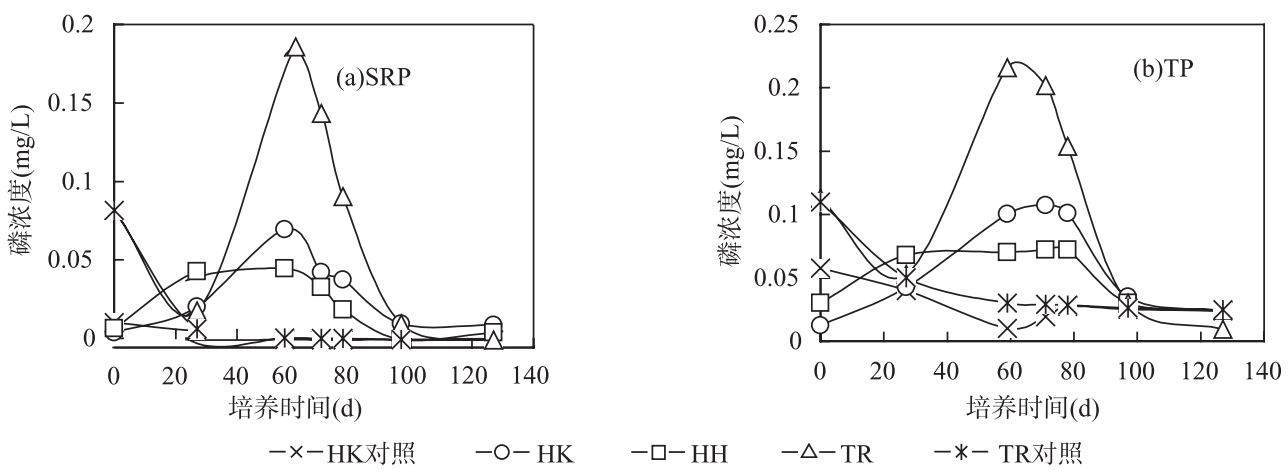

图 3 不同底质培养黑藻上覆水中磷浓度的变化

Fig.3 Variability of the phosphorus concentrations in the overlying water of different sediments

labile P 含量较高, 而 labile P 是底质中最容易释放的磷形态.

底质间隙水因富含内在磷负荷与动态补给等诸方面的重要意义而备受关注 ${ }^{[25]}$. 不同底质培养黑藻, 底质间隙水中磷含量变化如图 4 所示. HH 组、 HK 组沉积物间隙水中 SRP 呈 “抛物线” 型变化. TR 组呈 “S”型变化，总体上是下降. HK 对照组呈下降趋势. TR 对照组呈 “S”型变化, 但总体上是上升. 含量 大小顺序为 TR 组 $>\mathrm{TR}$ 对照组 $>\mathrm{HH}$ 组 $>\mathrm{HK}$ 组 $>\mathrm{HK}$ 对照组. 有植物组底质间隙水中 TP 均呈下降趋势, 对 照组与 SRP 变化相同, 含量大小顺序与 SRP 变化相同. 土壤作底质间隙水中 TP 及 SRP 含量高于沉积物, 表明土壤比沉积物能释放更多的磷或难以固定磷 ${ }^{[21]}$, 这可能是因为土壤中弱结合态磷和 RSP 含量较高. $\mathrm{HH}$ 组高于 HK 组, 可能是河流沉积物比湖泊沉积物能释放更多的磷或难以固定磷, 同时后海沉积物磷含 量较高, 具体原因还需进一步研究. 有植物组底质间隙水中磷含量高于对照组, 表明黑藻可以促进沉积 物中磷向间隙水中释放，从而被植物吸收及向水体释放.
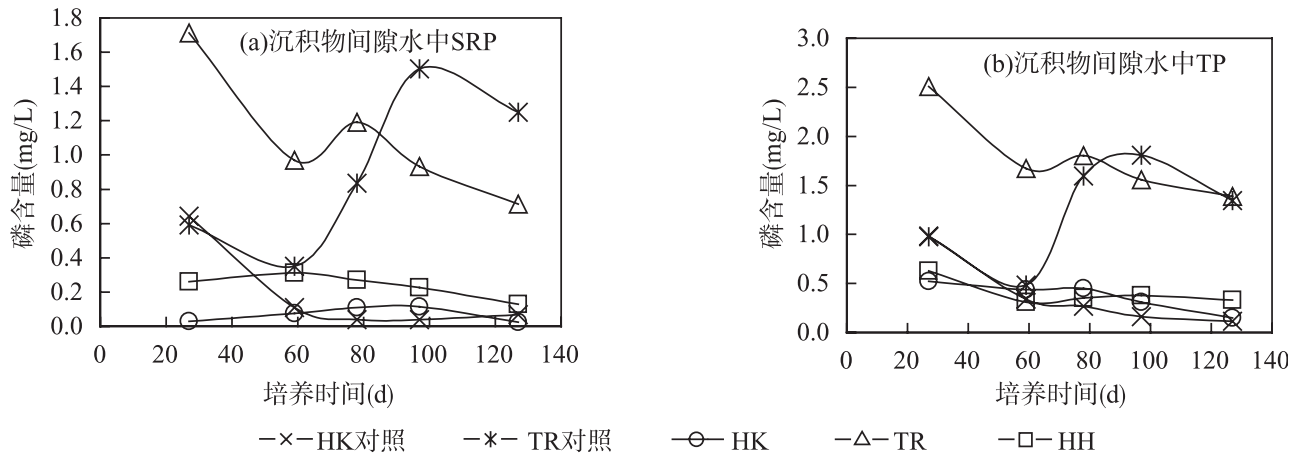

图 4 不同底质间隙水中磷含量变化

Fig.4 Variability of the phosphorus concentrations in the interstitial water of different sediments

间隙水是磷从底质释放至湖水的过度介质，间隙水中磷浓度的大小是底质磷丰度的反映并和磷的释 放相关 ${ }^{[14]}$. 间隙水中 SRP 与底质中不同形态磷相关分析 (表 6). 有植物组 Fe/Al-P 与间隙水中 SRP 均呈正 相关, 无植物组呈负相关. 表明有植物条件下随着底质中 Fe/Al-P 的增加间隙水中 SRP 浓度上升, 可能 是黑藻根系吸氧使沉积物中处于厌氧状态 Fe/Al-P 稳定性下降向间隙水中释放. TR 组间隙水中 SRP 与弱 结合态磷相关性显著, HH 组、HK 组中 SRP 与 RSP 相关性显著，表明淹水土壤间隙水中 SRP 受底质中弱 结合态磷含量所控制，沉积物间隙水中 SRP 受底质中 RSP 含量所控制 ${ }^{[24]}$. 无植物组间隙水中 SRP 与 labile P 相关性最大, 表明植物首先吸收底质中弱结合态磷. HH 组中 Fe/Al-P、Ca-P 均达到显著水平，可 
能是河流沉积物进人静止水体后, 水体流动减缓, 氧通量将低, 增强了底质中 Fe/Al-P 的活性, 河流沉积 物中 Ca-P 具有生物可利用性. 具体原因还需进一步验证.

表 6 底质中不同形态无机磷与间隙水中活性磷的相关性

Tab.6 The parameters of SRP in the interstitial water and the inorganic phosphorus forms in the sediments

\begin{tabular}{lllll}
\hline \multirow{2}{*}{ 相关系数 $\left(r^{2}\right)$} & \multicolumn{3}{c}{ 间隙水中活性磷 } \\
\cline { 2 - 5 } & labile P & RSP & Fe/Al-P & Ca-P \\
\hline HK & -0.37 & $-0.89^{* *}$ & 0.62 & -0.60 \\
HH & -0.07 & $-0.85^{*}$ & $0.77^{*}$ & $-0.76^{*}$ \\
TR & $0.96^{* *}$ & 0.20 & 0.64 & 0.65 \\
HK 对照 & $0.86^{*}$ & 0.46 & -0.16 & 0.36 \\
TR 对照 & $-0.76^{*}$ & -0.26 & -0.37 & 0.02 \\
\hline
\end{tabular}

*在 0.05 水平上显著相关, $* *$ 在 0.01 水平上显著相关; 样本数 $n=5$.

\section{4 底质中生物可利用磷的变化}

本文运用化学分析与生物测定相结合的方法, 估算不同沉积物中生物可利用磷含量变化及沉水植物 对其的影响. 初步根据藻类可利用颗粒态磷(AAPP)的估算公式 ${ }^{[26]}$ 估算生物可利用磷.

\section{$\mathrm{AAPP}=\Delta \mathrm{SRP}+\Delta \mathrm{PNH}_{4} \mathrm{Cl}+\Delta \mathrm{PBD}+\Delta \mathrm{PNaOH}+\Delta \mathrm{PHCl}$}

式中, $\Delta \mathrm{SRP}$ 表示无植物组 (CK 组) 和沉积物供磷组 (HK、TR 组) 上覆水中溶解态磷之差; $\Delta \mathrm{PNH}_{4} \mathrm{Cl}$ 、 $\Delta \mathrm{PBD} 、 \Delta \mathrm{PNaOH} 、 \Delta \mathrm{PHCl}$ 分别是无植物组 (CK 组) 和沉积物供磷组 ( $\mathrm{HK} 、 \mathrm{TR}$ 组) 各提取相含磷量 之差. 若用 $m$ 代表每千克沉积物中磷的含量 $(\mathrm{mg})$, 则 $\mathrm{HK}$ 组液相中磷浓度为 $m^{1 \mathrm{HK}}$, 各提取相磷浓度分别 为 $m^{\mathrm{NH} 4 \mathrm{ClHK}} 、 m^{\mathrm{BDHK}} 、 m^{\mathrm{NaOHHK}}$ 和 $m^{\mathrm{HClHK}} ; \mathrm{CK}$ 组液相中磷浓度为 $m^{1 \mathrm{CK}}$, 各提取相磷浓度分别为 $m^{\mathrm{NH} 4 \mathrm{ClCK}}$ 、 $m^{\mathrm{BDCK}} 、 m^{\mathrm{NaOHCK}}$ 和 $m^{\mathrm{HClCK}}$. 因此, $\mathrm{AAPP}(\mathrm{mg} / \mathrm{kg})=\left(m^{1 \mathrm{CK}}-m^{1 \mathrm{HK}}\right)+\left(m^{\mathrm{NH} 4 \mathrm{ClCK}}-m^{\mathrm{NH} 4 \mathrm{ClHK}}\right)+\left(m^{\mathrm{BDCK}}-m^{\mathrm{BDHK}}\right)+$ $\left(m^{\mathrm{NaOHCK}}-m^{\mathrm{NaOHHK}}\right)+\left(m^{\mathrm{HClCK}}-m^{\mathrm{HClHK}}\right)$.

2 种底质 AAPP 变化趋势均呈先上升后下降趋势, HK 作底质第 $97 \mathrm{~d}$ 时达到最大值, TR 作底质第 $59 \mathrm{~d}$ 时达到最大值(表 7). 各试验组无植物时(97d 以后)AAPP 趋近于 0, HK 作底质 $127 \mathrm{~d}$ 时 AAPP 出现负值可 能是黑藻腐烂沉积使有植物组沉积物磷含量升高. 底质中生物可利用磷的利用率为, HK 试验组 AAPP/NAIP 百分率在 0.08-105.45 之间, TR 试验组 AAPP/NAIP 百分率在 0.02-24.87 之间. 表明黑藻促进 底质中磷向可利用性转化, 黑藻对淹水土壤中生物可利用磷利用率比营养水平相当的沉积物低.

表 7 底质中生物可利用磷的变化

Tab.7 Variability of the bioavailable P in sediments

\begin{tabular}{llllllll}
\hline \multirow{2}{*}{ AAPP(mg/kg) } & \multicolumn{7}{c}{ 培养时间 $(\mathrm{d})$} \\
\cline { 3 - 8 } & 0 & 27 & 59 & 78 & 97 & 127 \\
\hline \multirow{2}{*}{$\mathrm{HK}$} & AAPP & 0.05 & 21.59 & 24.80 & 33.37 & 50.13 & -5.15 \\
& AAPP/NAIP(\%) & 0.08 & 38.11 & 55.13 & 75.04 & 105.45 & -13.45 \\
\hline \multirow{2}{*}{ TR } & AAPP & 0.03 & 21.23 & 43.23 & 19.90 & 10.81 & 0.12 \\
& AAPP/NAIP(\%) & 0.02 & 10.87 & 24.87 & 11.28 & 5.69 & 0.09 \\
\hline
\end{tabular}

\section{3 结论}

（1）在本试验条件下, 淹水土壤各形态磷活性大于营养水平相当的沉积物. 河流沉积物各形态磷活 性大于湖泊沉积物.

(2) 黑藻主要吸收利用底质中 labile P 及 RSP, 可以影响 Fe/Al-P 活性, 很难利用 Ca-P. 土壤进人湖泊 后不利于黑藻生长. 河流沉积物比湖泊沉积物有利于黑藻初期生长, 但容易使黑藻早衰.

（3）沉积物作底质上覆水、间隙水中磷浓度主要受底质中 RSP 的控制. 土壤作底质上覆水、间隙水 
中磷浓度受底质中 labile P 的控制.

(4) 黑藻促进底质中磷的生物可利用性，黑藻对淹水土壤中生物可利用磷的利用率比营养水平相当 的沉积物低

\section{4 参考文献}

[1] Vander Molen DT, Breeuwsma A, Boers PCM. Agricultural nutrient losses to surface water in the Netherlands: impact, strate-gies, and perspectives. J Environ Qual, 1998, 27: 4-11.

[2] 金相灿. 中国湖泊富营养化.中国湖泊环境. 北京: 海洋出版社, 1995: 267-322.

[3] 王晓燕. 农业非点源污染及其控制管理. 农业面源污染与综合防治, 2004, (11): 10.

[4]＼cjkstart杨＼cjkstart钢. 三峡库区受淹土壤污染物释放量的试验研究. 水土保持学报, 2004, 18(1): 111-114.

[5] Rossi G, Premazzi G. Delay in lake recovery caused by internal loading. Wat Res, 1991, 25: 567-575.

[6] 朱广伟, 秦伯强. 沉积物中磷形态的化学连续提取法应用研究. 农业环境科学学报, 2003, 22(3): 349-352.

[7] Fu YQ, Zhou YY, Li JQ. Sequential fractionation of reactive phosphorus in the sediment of a shallow eutrophic lake-Donghu Lake, China. Journal of Environmental Sciences, 2000, 12(1): 57-62.

[8] 李 伟, 钟 扬. 水生植被研究的理论和方法. 武汉: 华中师范大学出版社, 1992: 237-277.

[9] 马 凯, 蔡庆华, 谢志才等. 沉水植物分布格局对湖泊水环境 N、P 因子影响. 水生生物学报, 2003, 27(3): 232-237.

[10] 黄世玉, 黄邦钦. 不同磷源对藻类生长及其生化组成的影响. 台湾海峡, 1997, 16(4): 458-464.

[11] 高 丽, 杨 浩, 周健民等. 滇池沉积物磷的释放以及不同形态磷的贡献. 农业环境科学学报, 2004, 23(4): 731-734.

[12] Hupfer M, Gachter R, Giovanoli R. Transformation of phosphorus species in settling seston and during early sediment diagenesis. Aquatic Sciences, 1995, 57(4): 305-324.

[13] 郑爱榕, 沈海维, 李文权. 沉积物中磷的存在形态及其生物可利用性研究. 海洋学报, 2004, 26(4): 49-57.

[14] 付永清, 周义勇. 沉积物磷形态的分级分离及其生态学意义. 湖泊科学, 1999, 11(4): 376-381.

[15] 杨逸萍，胡明辉，陈海龙等. 九龙江口生物可利用磷的行为与人海通量. 台湾海峡, 1998, 17(3): 269-274.

[16] 杨逸萍, 宋瑞星, 胡明辉. 河口悬浮物与海洋表层沉积物中磷的海洋浮游藻类生物测定. 厦门大学学报(自然科学版), 1996, 35(4): 574-580.

[17] Qiu S, McComb AJ. Effects of oxygen concentration on phosphorus release from reflooded, air-dried wetland sediments. Aust J Mar Freshwat Res, 1994, 45(7): 1319-1328.

[18] Christensen KK, Wigand C. Formation of root plaques and their influence on tissue phosphorus content in Lobelia Dortmanna. Aquatic Botany, 1998, 61(2): 111-122.

[19] 金相灿, 姜 霞, 姚 杨等. 溶解氧对水质变化和沉积物吸磷过程的影响. 环境科学研究, 2004, 17(增刊): 34-39.

[20] 王晓蓉. 环境条件变化对太湖沉积物磷释放的影响. 环境化学, 1996, 15(1): 15-19.

[21] 徐轶群, 熊慧欣, 赵秀兰. 底泥磷的吸附与释放研究进展. 重庆环境科学, 2003, 25(11): 147-149.

[22] 陈国祥, 刘 双, 王 娜等. 磷对水生植物菱及睡莲叶生理活性的影响. 南京师大学报(自然科学版), 2002, 25(1): 71-76.

[23] 金相灿，王圣瑞，赵海超等. 磷形态对磷在水-沉水植物-底质中分配的影响. 生态环境, 2005, 14(5): 631-635.

[24] Reddy KR, Kadlee RH, F1aig E et al. Phosphorus retention in streams and waters: A review. Critical Reviews in Environmental Science and Technology, 1999, 29(1): 83-146.

[25] Psenner R, Puckso R. Phosphorus fractionation: advantages and limits of the methods for the study of sediment P and interactions. Arch Hydrobiol, 1988, 30: 43-59.

[26] 杨逸萍, 宋瑞星, 胡明辉. 河口悬浮物与海洋表层沉积物中藻类可利用颗粒磷的数量研究. 厦门大学学报(自然科学版), 1996, 35(6): 928-935. 